\title{
Components of the Development of Middle-Range Nursing Theories
}

\author{
Nuno Damácio de Carvalho Félix* \\ Health Sciences Center, Federal University of Recôncavo da Bahia, Brazil \\ *Corresponding author: Nuno Damácio de Carvalho Félix, Health Sciences Center, Federal University of Recôncavo da \\ Bahia, Santo Antônio de Jesus, Bahia, Brazil
}

\section{ARTICLE INFO \\ Received: 幽 September 02, 2020 \\ Published: 幽 September 16, 2020}

Citation: Nuno Damácio de Carvalho Félix. Components of the Development of Middle-Range Nursing Theories. Biomed J Sci \& Tech Res 30(3)-2020. BJSTR. MS.ID.004953.

\section{ABSTRACT}

The objective was to present a brief communication on the components of the development of middle-range nursing theories, based on international references of the discipline. These middle-range nursing theories must be presented as to the purpose, the propositions, or theoretical statements, the schematization or modeling, the assumptions and guidelines for use in practice, as well as in research, teaching and care management. To increase the visibility of nursing, it is highlighted that these theories must consider the phenomena of the discipline, in this case, the diagnoses, results and nursing interventions using a classification system, which can contribute to the generation of nursing care indicators.

Keywords: Nursing Theories; Middle-Range Theories; Method; Knowledge; Nursing Phenomena

\section{Introduction}

Nursing theories are a set of concepts that clarify nursing and the phenomena of its practice, to distinguish it from other disciplines, establishing the profession's limits for coordinated care $[1,2]$. These theories are categorized into the levels of abstraction in which metatheory, or philosophical questioning, clarifies major theories. These guide middle-range nursing theories that can guide practical theories, which in turn test middle-range nursing theories, perfecting the big theories [3]. It is a direct relationship between the levels of theoretical knowledge of the discipline that can also support other disciplines and that its use depends on the nurse's ability to link to professional practice. Nursing has sought to consolidate itself as a science to structure a body of knowledge specific to the discipline and increase professional visibility, with consequent impacts on teaching, research, practice, and management of nursing care, through nursing theories. To this end, this knowledge has been structured in nursing theories with varying levels of abstraction, but with a demand for approximation of great theories of nursing experiences. The objective was to present a brief communication on the components of the development of middle-range nursing theories, based on international references of the discipline.
The development of middle-range nursing theories that involves rigorous procedures that need to be detailed and described by the theorist according to his worldview. As for middle-range theories, this description has relevance when presenting the theorist's worldview, at the socio-cultural moment in which it is inserted, so that over time it can be analyzed for usefulness in society. The theorist needs to know and clearly delimit the phenomenon related to the developed theory, as well as the concept and clinical indicators. The development of middle-range nursing theories demands theoretical creativity, availability to receive criticism and knowledge of the specific phenomenon that will be theorized, that is, the knowledge of aspects of the reality of specificity under the theoretical view of the world. These phenomena must be described by concepts, to represent them and contribute to theorizing. These concepts must be directly related to nursing terminology for specificity presented by the theoretician, and the nursing classification system can be used, as well as produce new terminologies to be inserted in this system.

These middle-range nursing theories must be presented as to the purpose, the propositions or theoretical statements, the 
schematization or modeling, the assumptions and guidelines for use in practice, as well as in research, teaching and care management. These components must be developed using specific techniques or models such as concept analyzes, literature reviews, deductive processes derived from a great theory and/or inductive through research and the experience of the theorist. In this short communication, highlighted, the components for the development of middle-range nursing theories research are presented, following the references of internationally recognized authors, outlined in an appropriate, feasible and replicable way. Initially, the theorist must describe the study according to the design or type of study. It has been observed that a predominance of study of the theoretical or basic type, of a descriptive nature, but this description must be defined by the theoretical and justified within the study. It should be pointed out which is the theory development strategy (deductive, inductive, or hypothetical-deductive) depending on the central phenomenon/concept defined by the theorist. It is important that the theorist also classifies the theory according to the scope, so that it is possible to identify what the theorist's understanding is in relation to the field of insertion of the phenomenon in the nursing knowledge body.

The need to specify the theory's approach is highlighted. The approach as four possibilities, namely: theory-practice-theory (use of a non-nursing theory/borrowed theories to redefine the components according to the new theory); Practice-Theory (observation of the phenomenon of interest, analysis of similarity and difference, with theoretical derivation from clinical situations); research-theory (selection of a phenomenon of interest, description of its characteristics, in which the research findings support the theory); and theory-research-theory (modification to improvement/testing of the theory based on research, a new theory can be formed) [4]. These initial components contribute to the clear specification of the purpose of the theory, explaining the purpose of the development, relating it to the specific context of nursing care, socio-political and clinical-epidemiological. Authors [2] present that this description of the purpose is usually explicit in the discussion of the theory. This specification will facilitate the structuring of the theory's development stages, which must be related to the previous components, following appropriate techniques, described in detail, and executed in a rigorous manner, respecting the theoretical autonomy of the theorist.

The steps may include the contextualization of theoretical development and its purpose, previously defined, the analysis of the concept/analysis of the theory depending on the strategy of development of the theory; identification and definition of theoretical propositions and assumptions, modeling the theory and guidance for using the theory. These stages can have their order adjusted and varied according to each methodological path, always following justification, with scientific rigor and creative autonomy of the theorist. There is a tendency to start theorizing through concept analysis, depending on the number of central phenomena. At this stage, there is a need to select the concept analysis technique/model according to the concept to be analyzed. The models most used in nursing are proposed by authors [3-6], but others can be used depending on the concept and theory to be developed. Considering the deductive strategy of developing theories, there is a need to carry out the synthesis and theoretical derivation. For this, the ability to visualize the analogical dimension of the phenomenon in two contexts, or distinct fields of interest and the ability to redefine and transpose the content and structure of one context or field to another is required [3]. In this proposal, the main components (concepts, propositions, modeling, and assumptions) of great theories are approximated to more concrete phenomena, paying attention to the selection of the great theory suitable for theoretical derivation.

Theory's propositions are understood as the relationship between two or more concepts and are used to connect concepts in the creation of theories before making explanations or predictions [7]. These are definitions for the concepts of a theory in which alignment with the phenomenon is suggested, correlating with the concepts of the Nursing metaparadigm, at least the concepts and definitions of person, health, environment, and nursing in relation to the specificity of the theory. These concepts defined by propositions must be represented by a modeling, in which there is a schematic representation of the relationships between the concepts and which present some aspects of reality, by various means, such as geometric shapes and diagrams [7]. This component explores the theorist's creativity, knowledge of the phenomenon and its relationship with the components of the theory to be evaluated and tested. Assumptions are factual statements known from experience or they may reflect positions of value that imply what is right, what is good or should be [2]. They must be elaborated through the body of knowledge developed and integrated in the empirical bases, outlined in the modeling of the theory to guide the developed theory regarding the evaluation and testing of the theory in practice.

Middle-range nursing theories should provide guidelines for use in practice, and if possible, in teaching, research and management. These guidelines may vary according to the characteristics and phenomenon of the theory, but there is the possibility of using a classification system in nursing to standardize and generate indicators of nursing care and health arising from the theory test, consolidating it as the relevance for nursing and health. Other possibilities involve the presentation of the difference in relation to the theories that already exist in the priority area, the construction of instruments to stimulate the use of the theory (protocols, software, scales). There is an understanding of the usefulness and validity of middle-range nursing theories, in which there is a need to define the limit of the theory (up to which scope of health it applies) and the testing of concepts, or part of the concepts, in practice through clinical research, preferably with robust studies that contribute to 
the generation of scientific evidence for nursing and health, which can be pointed out by the theorist in the theory itself, but without limiting the possibilities of those who propose to use and research based on theory. To increase the visibility of nursing, it is highlighted that these theories must consider the phenomena of the discipline, in this case, the diagnoses, results and nursing interventions using a classification system, which can contribute to the generation of nursing care indicators. In this case, the use of a single nursing phenomenon, for example, a nursing diagnosis, makes the theory more practical and specific, but does not reduce its relevance. Likewise, the greater the number of nursing phenomena contained in the theory, the more comprehensive the theory will be.

\section{Conflict of Interest}

The author declares no conflicts of interest

\section{References}

1. Alligood MR (2013) Nursing theory: utilization and application. St Louis (US): Elsevier Mosby.

\section{ISSN: 2574-1241}

DOI: $10.26717 /$ BJSTR.2020.30.004953

Nuno Damácio de Carvalho Félix. Biomed J Sci \& Tech Res

(c) This work is licensed under Creative

Submission Link: https://biomedres.us/submit-manuscript.php
2. Chinn PL, Kramer MK (2011) Integrated theory and knowledge development in nursing. St Louis (US): Mosby.

3. Walker LO, Avant KC (2019) Strategies for theory construction in nursing In Walker LO, Avant KC (Eds.), (6 $6^{\text {th }}$ edn.), New York (US): Pearson.

4. Meleis AI (2012) Theoritical nursing: Development and progress. In Meleis AI (Eds.), (5 ${ }^{\text {th }}$ edn.), Philadelphia: Lippincott Williams \& Wilkins.

5. Schwartz Barcott D, Kim HS (2011) An expansion and elaboration of the hybrid model of concept development. In Rodgers BL, Knafl KA (Eds.), Concept Development in Nursing: Foundations, Techniques, and Applications, ( $2^{\text {nd }}$ edn.), Philadelphia: W.B. Saunders.

6. Rodgers BL (2000) Concept analysis: an evolutionary view. In: Rodgers BL, Knafl KA (Eds.), Concept Development in Nursing: Foundations, Techniques, and Applications. (2 ${ }^{\text {nd }}$ edn.) Philadelphia (US): W.B. Saunders p. 77-102

7. McEwen M, Wills EM (2016) Bases teóricas de enfermagem. In McEwen M, Wills EM (Eds.), ( $4^{\text {th }}$ edn.) Porto Alegre: Artmed.

$\begin{array}{ll}\text { BIOMEDICAL } & \text { Assets of Publishing with us } \\ \text { RESEARCHES } & \text { - Global archiving of articles } \\ \text { - Immediate, unrestricted online access } & \text { - Rigorous Peer Review Process } \\ & \text { - Authors Retain Copyrights } \\ \end{array}$

